\title{
AS EDUCAÇÕES NA POLÍTICA DE ASSISTÊNCIA SOCIAL EM CONVERGÊNCIAS EMANCIPATÓRIAS ${ }^{1}$
}

\author{
EDUCATIONS IN THE SOCIAL ASSISTANCE POLICY IN \\ EMANCIPATORY CONVERGENCES
}

\section{LAS EDUCACIONES EN LA POLIITICA DE ASISTENCIA SOCIAL EN CONVERGENCIAS EMANCIPATORIAS}

\author{
Levi Nauter de Mira² \\ ORCID: https://orcid.org/0000-0002-6846-8174 \\ Danilo Romeu Streck ${ }^{3}$ \\ ORCID: https://orcid.org/0000-0001-7410-3174.
}

\begin{abstract}
Resumo: Este texto apresenta argumentos em favor de uma educação que adentra todos os espaços da vida cotidiana. É fruto de pesquisa realizada no município de Novo Hamburgo, Rio Grande do Sul, com educadores e educadoras sociais que atuam no Serviço de Convivência e Fortalecimento de Vínculos em organizações governamentais e não governamentais. Desse modo, expõe-se um panorama do campo da política de assistência social no Brasil, em que atuam tais educadores e educadoras, destacando a importância de alguns documentos que apontam para o tema da emancipação. A pesquisa qualitativa foi feita em documentos normativos da assistência social, bem como na epistemologia que sustenta cada uma das educações a partir das quais os dados empíricos produzidos foram analisados. Com base nas observações feitas durante a pesquisa, percebeu-se um diálogo entre diferentes princípios educativos. Assim, as educações mais perceptíveis foram a educação não escolar, a educação popular, a educação social crítica e a educação permanente. Concluiu-se que há convergências que visem à emancipação tanto no campo educacional como no campo da política de assistência social, sobretudo a partir de teorias críticas.
\end{abstract}

Palavras-chave: Educação popular. Educação social. Assistência social. Educação não escolar. Emancipação.

Abstract: This text presents arguments in favor of an education that covers all spaces of daily life. It is the result of a research carried out in Novo Hamburgo county, Rio Grande do Sul, Brazil, with social educators who act on

1 Este texto baseia-se em uma pesquisa realizada e apresentada como tese de doutorado (MIRA, 2020) e contou com o apoio da Coordenação de Aperfeiçoamento de Pessoal de Nível Superior - Brasil (Capes) - Código de Financiamento 001.

2 Universidade do Vale do Rio dos Sinos (Unisinos). São Leopoldo - RS, Brasil.

3 Universidade de Caxias do Sul (UCS), Caxias do Sul - RS, Brasil 
the Service of Living Together and Strengthening of Bonds in governamental and non-governamental organizations. Thus, an overview of the field of social assistance policy in Brazil is presented, in which these educators enact, highlighting the importance of some documents that point to the theme of emancipation. The qualitative research was carried out on normative documents of social assistance, as well as on the epistemology that supports each of the educations from which the empirical data produced were analyzed. Based on the observations made during the research, a dialogue between different educational principles was perceived. Thus, the most perceptive educations were the non-formal school education, the popular education, the socio-critical education and the permanent education. It was concluded that there are convergences aimed at emancipation both in the educational field and in the field of social assistance policy, especially from critical theories.

Keywords: Popular Education. Social Education. Social Assistance. Non-School Educational. Emancipation.

Resumen: Este texto presenta argumentos en favor de una educación que adentra todos los espacios de la vida cotidiana. Es fruto de investigación realizada en la ciudad de Novo Hamburgo en Rio Grande do Sul, Brasil, con educadores y educadoras sociales que actúan en el Servicio de Convivencia y Fortalecimiento de Vínculos en organizaciones gubernamentales y no gubernamentales. De ese modo, se expone un panorama del campo de la política de asistencia social en Brasil, en el que actúan tales educadores y educadoras, destacando la importancia de algunos documentos que apuntan para el tema de la emancipación. La investigación cualitativa ha sido hecha en documentos normativos de la asistencia social, bien como en la epistemología que sustenta cada una de las educaciones a partir de las cuales fueron analizados los datos empíricos producidos. Con base en las observaciones hechas durante la investigación, se ha percibido un diálogo entre diferentes principios educativos. Así, las educaciones más perceptibles fueron la educación no escolar, la educación popular, la educación social crítica y la educación permanente. Se concluye que hay convergencias que objetivan la emancipación tanto en el campo educacional como en el campo de la política de asistencia social, sobre todo a partir de teorías críticas.

Palabras clave: Educación Popular. Educación Social. Asistencia Social. Educación No Escolar. Emancipación.

\section{INTRODUÇÃO}

É cada vez mais consensual que a educação transcende a escola e se entranha em todas as instâncias da nossa vida (BRANDÃO, 2007; LIBÂNEO, 2002). A ideia de que aprendemos ao longo da vida ou permanentemente corrobora a extrapolação do ambiente escolar. Isso permite entendermos que cada ação, desde a que se nomina como rotineira até a mais complexa, pode se transformar em um momento pedagógico de reflexão e de aprendizagens.

A pesquisa que realizamos no município de Novo Hamburgo, Rio Grande do Sul (RS), envolveu duas organizações governamentais e duas organizações não governamentais. Observações participantes (ANGROSINO, 2009) e entrevistas compreensivas (KAUFMANN, 2013) foram realizadas com educadores e educadoras sociais que, nessas organizações, executam o Serviço de Convivência e Fortalecimento de Vínculos (doravante apenas Serviço de Convivência) junto a crianças e adolescentes. A centralidade da pesquisa esteve em verificar como as práticas desses educadores e dessas educadoras sociais contribuíam para o enfrentamento das vulnerabilidades sociais de cidadãos e cidadãs que buscavam socorro do Estado. 
Realizamos as entrevistas em meio às observações participantes. A partir das falas dos educadores e das educadoras, percebemos a necessidade de também entrevistarmos outros trabalhadores e outras trabalhadoras que compõem o quadro profissional da política de assistência social. Para preservarmos suas identidades, os sujeitos da pesquisa foram identificados da seguinte forma: os educadores e as educadoras sociais como Coletivo Educador Social; aqueles e aquelas que compunham o quadro técnico das organizações pesquisadas como Coletivo Técnico; os/as atuantes na Secretaria Municipal de Desenvolvimento Social foram designados/as como Coletivo Gestor. Tais coletivos tiveram como base as ideias de Lefèvre (2017), que propõe um discurso do sujeito coletivo. Entretanto, diferentemente da proposta de Lefèvre (2017), o sujeito coletivo nesta pesquisa não se relacionou com alguma eventual unicidade discursiva, mas tão somente pelo lugar de trabalho que cada grupo que foi entrevistado. Especialmente neste texto, concentramo-nos, unicamente, na ação de educadores e educadoras sociais.

Em meio à pesquisa, percebemos uma multiplicidade de práticas educativo-pedagógicas que poderiam ser pensadas a partir de algumas vertentes teóricas. Escolhemos refletir sobre essas práticas a partir da teoria crítica. Com esse intento, além desta introdução e das considerações finais, organizamos o texto em duas partes. Na primeira, abordamos pontos fundamentais da história da política de assistência social, enfatizando o conjunto normativo-jurídico que a sustenta. Buscamos trazer o conceito de emancipação de que os documentos Tipificação Nacional de Serviços Socioassistenciais (BRASIL, 2013a) e Política Nacional de Educação Permanente do SUAS (Sistema Único de Assistência Social) (BRASIL, 2013b) falam e a prática que observamos nos educadores e nas educadoras sociais. Na segunda parte, apresentamos as educações que, em nosso entender, podem levar as pessoas que buscam socorro no Estado a pensar na transformação de suas realidades. Nas considerações finais, reforçamos a ideia de que a educação pode estar em todas as instâncias dos afazeres diários.

\section{A POLÍTICA DE ASSISTÊNCIA SOCIAL: ANTIGOS E NOVOS TEMPOS}

Mesmo entendendo que em um artigo não se esgota um tema de tamanha densidade, gostaríamos de registrar um caminho histórico. Nesse sentido, a política de assistência social brasileira teve uma ligação mais estreita com a polícia do que com a política. Desse tempo, herdamos, por exemplo, a ideia de delinquência a respeito do menor. Politicamente, passamos a verificar um gerenciamento - ainda hoje persistente - do social pelas primeiras-damas. Algumas mudanças significativas começaram a ocorrer a partir da promulgação da Constituição Federal de 1988, também conhecida como Constituição Cidadã. Com ela, cidadãos e cidadãs passaram a conquistar alguns direitos que, aliados à luta de movimentos sociais, foram impondo uma mudança de percepção na sociedade. A aprovação do Estatuto da Criança e do Adolescente (ECA), em 1990, foi como que forçando a sociedade 
a ver esse público como pessoas em processo de desenvolvimento, não mais como delinquentes. A Lei Orgânica da Assistência Social, em 1993 - Lei № 8.742, de 7 de dezembro de 1993 -, foi outro avanço; ela consolidou a assistência social como um direito do cidadão e um dever do Estado (BRASIL, 1993).

Como toda a legislação retrata o período em que foi editada, tem-se atualizações, emendas e outras normativas que visam a consolidar a cidadania e deixar de lado a ideia de favor estatal ou bondade de algum governante. Por isso, compreendemos ser necessário nominar aqueles e aquelas que recorrem ao direito de serem socorridos/as pelo Estado como "cidadãos/cidadãs usuários/as". A Carta Magna informa quem eles e elas são: cidadãos e cidadãs; as normas no campo da assistência social lhes identifica: usuários e usuárias. Ora, são primeiro cidadãos/cidadãs e, como consequência, podem vir a ser usuários/usuárias (LEMES, 2017; SPOSATI, 2007). Assim, entendemos que todas as pessoas atendidas nos serviços socioassistenciais têm de ser reconhecidas como cidadãos ou cidadãs usuários/as.

O documento Tipificação Nacional de Serviços Socioassistenciais (BRASIL, 2013a) apresenta um quadro síntese (Quadro 1) importante a respeito dos serviços disponíveis a cidadãos e cidadãs usuários/as.

Quadro 1 - Serviços Socioassistenciais

\begin{tabular}{|c|c|c|}
\hline \multicolumn{2}{|c|}{ PROTEÇÃO SOCIAL BÁSICA } & $\begin{array}{l}\text { 1. Serviço de Proteção e Atendimento Integral à } \\
\text { Família (PAIF); } \\
\text { 2. Serviço de Convivência e Fortalecimento de } \\
\text { Vínculos; } \\
\text { 3. Serviço de Proteção Social Básica no Domicílio } \\
\text { para Pessoas com Deficiência e Idosas. }\end{array}$ \\
\hline \multirow[t]{2}{*}{$\begin{array}{c}\text { PROTEÇÃO } \\
\text { SOCIAL } \\
\text { ESPECIAL }\end{array}$} & $\begin{array}{c}\text { Média } \\
\text { Complexidade }\end{array}$ & $\begin{array}{l}\text { 1. Serviço de Proteção e Atendimento Especializa- } \\
\text { do à Famílias Indivíduos (PAEFI); } \\
\text { 2. Serviço Especializado em Abordagem Social; } \\
\text { 3. Serviço de proteção social a adolescentes em } \\
\text { cumprimento de medida socioeducativa de Liber- } \\
\text { dade Assistida (LA) e de Prestação de Serviços à } \\
\text { Comunidade (PSC); } \\
\text { 4. Serviço de Proteção Social Especial para Pes- } \\
\text { soas com Deficiência, Idosas e suas Famílias; } \\
\text { 5. Serviço Especializado para Pessoas em Situa- } \\
\text { ção de Rua. }\end{array}$ \\
\hline & Alta Complexidade & $\begin{array}{l}\text { 6. Serviço de Acolhimento Institucional; } \\
\text { 7. Serviço de Acolhimento em República; } \\
\text { 8. Serviço de Acolhimento em Família Acolhedora; } \\
\text { 9. Serviço de proteção em situações de calamida- } \\
\text { des públicas e de emergências. }\end{array}$ \\
\hline
\end{tabular}

Fonte: Brasil (2013a, p. 10, grifos do autor). 
Verificamos, no Quadro 1, que os serviços possuem a seguinte divisão: a proteção social básica e a especial. Na básica, o objetivo é "[...] fortalecer a função protetiva das famílias, prevenir a ruptura dos seus vínculos, promover seu acesso e usufruto de direitos" (BRASIL, 2013a, p. 12), enquanto a proteção social especial tem a finalidade de apoiar, orientar e acompanhar as famílias nas quais "um ou mais de seus membros" estejam "[...] em situação de ameaça ou violação de direitos" (BRASIL, 2013a, p. 29). O trabalho possui matricialidade sociofamiliar, isto é, a centralidade passa do indivíduo para a família na qual ele está inserido. Cidadãos ou cidadãs usuários/as dos serviços socioassistenciais devem ser vistos/as a partir de uma coletividade que os/as cercam - primeiramente a família; em seguida, a comunidade em que vivem (SPOSATI, 2007).

Nossa pesquisa ocorreu no Serviço de Convivência. Ele é parte dos serviços de proteção básica e atende a todos os ciclos de vida. Há cidadãos e cidadãs usuários/as sendo atendidos/as semanalmente, em horários e turnos diversos, com os/as quais uma série de atividades educativo-pedagógicas são desenvolvidas. São momentos educativos porque tanto os cidadãos e as cidadãs usuários/as quanto os trabalhadores e as trabalhadoras estão, ao mesmo tempo, ensinando e aprendendo. Igualmente, são pedagógicos, na medida em que, previamente pensados e planejados, possuem intencionalidades e visam a chegar em algum lugar.

Mais uma vez, recorremos à Tipificação Nacional de Serviços Socioassistenciais (BRASIL, 2013a). O documento alerta-nos que as ações, considerando a centralidade da família, devem prever a intergeracionalidade e a heterogeneidade "[...] na composição dos grupos por sexo, presença de pessoas com deficiência, etnia, raça, entre outros" (BRASIL, 2013a, p. 16). A contribuição do campo educacional para a política de assistência social pode estar na forma de

[...] intervenção social planejada que cria situações desafiadoras, estimula e orienta os [cidadãos] usuários na construção e reconstrução de suas histórias e vivências individuais e coletivas [...]. [Nas ampliações de] trocas culturais e de vivências [...] com vistas ao alcance de alternativas emancipatórias para o enfrentamento da vulnerabilidade social. (BRASIL, 2013a, p. 16, grifos nossos).

A contribuição da educação, conforme a leitura do trecho grifado, deve ter a perspectiva emancipatória, por nós também entendida como autônoma. O tema não contradiz o pensamento de Adorno (1995), para quem a emancipação equivale a um processo contínuo de conscientização que vai gerando independência nas tomadas de decisões. Assim, o filósofo compreendia que a democracia carecia de pessoas emancipadas - pois nenhuma delas, democracia e emancipação, tornar-se-iam conquistas acabadas em si mesmas, antes, porém, avanços civilizatórios que constantemente precisariam ser revisitados, fortalecidos e ampliados. 
No contexto latino-americano, em que países periféricos buscam consolidar suas democracias, trabalhar sob o viés emancipatório é ainda mais urgente. Desse ponto de vista, Streck e Adams (2014, p. 67) interpretam a emancipação e a autonomia como um "[...] libertar-se do jugo, da tutela de alguém. [...] não mais escravo ou indivíduo dependente; libertar-se do poder exercido por outros". Notemos que Adorno (1995) entende a emancipação, a autonomização como fruto da conscientização. Portanto, a liberdade de cidadãos e cidadãs tomarem as próprias decisões terá eficácia na medida da consciência de suas responsabilidades, de seus direitos, de seus deveres. Tem a ver com atitudes que não se descolam da justiça social e visam à superação das desigualdades, sem abrir mão de uma sociedade sustentável. Streck e Adams (2014), nesse intento, sugerem que pode haver indícios, sinais a partir dos quais se evidencia estar ocorrendo a emancipação. Dos elementos indicativos, destacamos: a) o entendimento de que benefícios sociais são direitos do cidadão e da cidadã e não dádiva ou dívida que se contrai com governantes; b) o exercício constante de respeito às diferenças; c) a busca por uma convivência e/ou vivência de relações igualitárias no ambiente familiar, no ambiente comunitário; d) a participação em projetos que visem à superação das desigualdades e melhorem as condições de vida; e) uma alimentação mais saudável e valorização do lazer; f) a produção e a organização de serviços solidários e de consumo solidários e conscientes, fortalecendo a justiça e a ética.

Esses sinais indicativos de emancipação vão ao encontro da Tipificação Nacional de Serviços Socioassistenciais (BRASIL, 2013a, p. 16), no que tange à criação de "situações desafiadoras", nas quais a realidade dos cidadãos e das cidadãs usuários/as possa ser pensada no enfrentamento das vulnerabilidades. Certamente, é um desafio que não se resolve de uma hora para outra, mas demanda tempo, investimento em diálogo e em estudos.

Nas práticas que observamos, o público não era adulto. No entanto, o Coletivo Educador Social entendia a importância de ensinar os sinais de possível emancipação às crianças e aos/às adolescentes, pois, de alguma forma, iria repercutir na casa onde moravam com adultos: a importância da higiene, da limpeza, da organização dos materiais de uso comum; de como é bom alimentar-se de maneira mais saudável, aproveitando bem os alimentos; as aprendizagens sobre a reciclagem - tanto para o meio ambiente quanto para aquelas pessoas que sobrevivem dessa atividade; a relevância dos encontros, das reuniões e das brincadeiras coletivas; da voz e da vez de cada um dizer o que pensa e como pensa. De um modo geral, educadores e educadoras sociais utilizaram a ludicidade para ir orientando as famílias nesses entendimentos. Contudo, as práticas e o andamento dos trabalhos, no dia a dia, nem sempre transcorreram como o planejado. Por isso, os sinais de emancipação são horizontes a serem perseguidos.

O campo educacional possui uma multiplicidade de práticas pedagógicas que podem contribuir na reflexão de cidadãos e cidadãs. A essa pluralidade chamamos educações. No Serviço de Convivência, pareceu-nos que as práticas de educadores e educadoras sociais poderiam ser vistas a partir de diversas vertentes teórico-educativas em diálogo. Nós, 
porém, escolhemos quatro educações a partir das quais refletimos sobre as práticas que observamos.

\title{
EDUCAÇÕES QUE PODEM EMANCIPAR
}

\author{
Pra mim é um suporte né, não é professor. É o suporte entre família, escola e o \\ educador social no meio. Aqui a gente consegue fazer coisas que o professor não \\ consegue e que a família não está conseguindo.
}

(Coletivo Educador Social).

É certo que o ambiente educativo no campo da política de assistência social difere do campo escolarizado. Nele, porém, também ocorrem o que chamamos educações, inspirados em Gadotti (2012) e em Mejía (2018). A pesquisa fez-nos perceber que trabalhadores e trabalhadoras do Serviço de Convivência lançavam mão de diversas estratégias, às vezes lembrando a escola e em outras procurando dela distanciar-se - como podemos verificar na fala destacada na epígrafe anterior. Havia um entrecruzamento de práticas pedagógicas que, de certa forma, possuíam afinidades.

Porque o ambiente não é o mesmo da escola, a educação não escolar se torna uma concepção teórica importante para refletirmos as práticas. Quando pensamos na orientação do documento Tipificação Nacional de Serviços Socioassistenciais (BRASIL, 2013a), cuja ideia é a de que cidadãos e cidadãs usuários/as repensem suas histórias de vida a fim de modificá-las e rumarem a uma emancipação, há outras duas educações que podem ajudar nesse caminho: a educação popular e a educação social crítica. Outra importante reflexão que se faz necessária diz respeito à formação e à qualificação dos trabalhadores e das trabalhadoras do campo da política de assistência social, levando-se em conta o que a prática - na proteção social básica, por exemplo - exigirá. Por isso, a educação permanente é outra concepção que nos interessará.

Portanto, as educações que escolhemos como referência foram: a educação não escolar, a educação popular, a educação social crítica e a educação permanente. Em comum, entre elas, está a estreita relação com a teoria crítica. Vejamos cada uma delas mais de perto.

\section{EDUCAÇÃO NÃO ESCOLAR}

Essa concepção teórica tornou-se relevante diante de uma recorrente fala: "isso aqui não é uma escola", e, em não sendo, haveria de ser caracterizada. Martins (2016, p. 42) entende educação não escolar como "[...] a mais producente denominação dos processos educativos que se desenvolvem fora da escola". Isso porque as intencionalidades são intrínsecas mesmo sem a consciência de suas imanências. Se levarmos em conta que somos sujeitos aprendentes para toda a vida, não é de estranharmos que tais aprendizagens 
extrapolem os muros da escola nem que a complexidade das relações esteja refletida em ambos os espaços - escolares e não escolares. O autor identifica algumas razões para sua defesa: a) as experiências desenvolvidas fora da escola e voltadas para a formação humana têm cunho educativo; b) tais eventos cotidianos ocorrem desde antes da escola ser "inventada", como resultados da interação humana que adentra todos os espaços em que a vida acontece e são "[...] tomados como objeto de análise e compreensão de pedagogos e estudiosos das ciências humanas e sociais" (MARTINS, 2016, p. 50).

Para nossos estudos, as autoras Moura e Zucchetti $(2006,2010)$ foram importantes na medida em que seus trabalhos deixam claro não haver como fugir de algumas formalidades, tendo em vista o aparato burocrático de controle do Estado quando uma instituição se lança ao trabalho junto aos chamados vulnerabilizados, pois

[...] as entidades de caráter social, educativas ou de qualquer outra natureza, que se dedicam à proteção da infância e da juventude devem formalizar e justificar as suas ações numa rede social mais ampla, a fim de legitimar o seu projeto e sua prática pedagógica e, de certa forma, ter o "aceite" prévio de um ente reconhecido organizador da política, no âmbito dos municípios. Os Conselhos Municipais da Criança e do Adolescente são um exemplo. (MOURA; ZUCCHETTI, 2010, p. 631).

O excerto anterior diz-nos que ficaria prejudicado o uso do termo "educação não formal", tendo em vista haver formalidades - e não poucas. Ademais, as autoras ainda asseveram que "[...] a educação escolar traz consigo a sua complementaridade: a educação não escolar" (MOURA; ZUCCHETTI, 2010, p. 630). Diante disso, podemos destacar como importantes características dessa educação a liberdade curricular, a escolha de temas diversos a serem trabalhados sem nenhuma pressão por conclusão nem por atribuição de um valor (nota, conceito, parecer). Essa educação que não concorre com a escolar tem como horizonte dar sentido pedagógico a práticas que, não raras vezes, vêm sendo trabaIhadas de maneira intuitiva.

\section{EDUCAÇÃO POPULAR}

Entendemos a educação popular como a maior contribuição latino-americana para a pedagogia mundial. Tal como o continente onde ela nasce, é permeada de idiossincrasias, o que nos permite dizer que temos pedagogias (MEJÍA, 2018). AAmérica Latina possui realidades diversas e Mejía (2018) faz um bom apanhado dessa diversidade. Além dele, uma rápida consulta eletrônica mostra-nos uma farta bibliografia sobre essa educação. Dessa forma, neste texto, concentramo-nos mais objetivamente nas razões de entendermos por que a educação popular pode contribuir na reflexão sobre as práticas educativas na política de assistência social. 
Desde o início do século passado, encontram-se registros de movimentos ligados a uma educação de resistência, que, mais tarde, viria ganhar o nome "educação popular". Paiva (2003) e Ferraro (2009) destacam a celeuma do analfabetismo como um impeditivo para o tão sonhado desenvolvimento brasileiro comparado ao cenário mundial.

Paiva (2003) argumenta que a preocupação com a educação estava ligada à ideia de que ela traria o progresso. Além disso, sinaliza que havia uma preocupação eleitoreira, no sentido do aumento de votantes. Ao vir o tal progresso, aliado ao aumento substancial de eleitores, passar-se-ia a ideia de um Brasil pujante - o que, para organismos internacionais, poderia ser interessante mostrar. Ferraro (2009) entende que o analfabetismo passou a ser um problema quando se ligou à questão eleitoral. E vem, desde então, uma ideia que persegue cidadãos e cidadãs usuários/as da política de assistência social: se sabem menos, geralmente são tidos/as como incapazes, ignorantes e dependentes.

A educação popular, a partir dos anos de 1960, ganhou notoriedade muito em razão dos trabalhos coordenados por Paulo Freire e sua equipe (FÁVERO, 2013), assim como sua concepção de educação "junto", "com” e a defesa da conscientização como possibilidade de mudança (BEISIEGEL, 1992).

Hoje, dificilmente quem lida com a educação popular nega seu aspecto político. Pode haver divergência (e há) no sentido daquilo que se denomina educação popular ou de sua abrangência (BRANDÃO, 2007; PAIVA, 2003). Entretanto, há de admitirmos que a institucionalização dificulta uma presença mais efetiva nas lutas de libertação das classes subalternas. Em outras palavras, a política de assistência social, institucionalizada e, inclusive, com procedimentos padronizados, dificulta a presença de práticas que visem à emancipação.

Uma das experiências encontradas no campo empírico foi denominada mapas falados. Nela, cidadãos e cidadãs usuários/as, a partir de suas próprias ópticas, desenhavam seus bairros (ruas, praças, escolas, igrejas etc.), contavam sobre as violências enfrentadas (a vulnerabilidade contada) e diziam de seus sonhos para aqueles lugares. Para essas atividades, educadores e educadoras sociais visitavam as casas e propunham a construção desses mapas falados com mais de uma família reunida. Esse fazer pedagógico aproximou educadores e educadoras dos moradores e estes puderam compartilhar seus sonhos e desejos de transformação daqueles lugares. Se, de um lado, nem tudo o que o cidadão ou a cidadã deseja é prontamente realizável; de outro, podemos pensar em uma agenda de quefazeres do poder público para com os cidadãos e as cidadãs do município. Assim, podemos, mais concretamente, pensar em uma transformação dos lugares onde estão os sujeitos para os quais os serviços públicos são oferecidos.

A educação popular pode ser um importante instrumento no diálogo educativo-pedagógico na medida em que se fundamenta em processos de conscientização da realidade com vistas à mudança. É também uma característica dessa educação incentivar à cidadania. Nesse sentido, o documento Tipificação Nacional de Serviços Socioassistenciais 
(BRASIL, 2013a, p. 9) deixa claro o que intenta aos cidadãos e às cidadãs usuários/as: "[...] mudanças efetivas e duradouras em sua condição de vida, na perspectiva do fortalecimento de sua autonomia e cidadania". Ora, a educação popular, não sendo neutra nem negando sua politicidade, busca justamente a mudança na sociedade e a conscientização de que outro mundo é possível.

\section{EDUCAÇÃO SOCIAL CRÍTICA ${ }^{4}$}

A educação social possui vertentes (PÉREZ SERRANO, 2002, 2010; PETRUS, 1997; VARELA; COTOS, 2010) que, em razão da limitação de um artigo científico, não serão abordadas. No entanto, para termos uma ideia, basta dizermos que Hitler se utilizou da educação social (CABANAS, 1997; PÉREZ SERRANO, 2010). Desse modo, entendemos como necessário dizermos de qual educação social estamos falando.

Em nosso caso, referimo-nos à educação social crítica, nascida em 1968, a qual consistia "[...] em llevar a cabo una educación emancipatória en un proceso dinámico, entendiendo al sujeto como un individuo con sus problemas, deseos, ideas y experiencias biográficas" (PÉREZ SERRANO, 2002, p. 222). Um grupo de estudiosos criticava o enfoque liberal, positivista, da educação social até então, propondo uma versão socialista-marxista.

Enquanto isso, é importante notarmos que, na América Latina, ocorriam fatos paralelos (ver PRADO; PELLEGRINO, 2016). Se, na Europa, havia questionamentos como espécie de rescaldo da revolução industrial, assentadas nas leituras marxistas; aqui, os latino-americanos envolviam-se em sua libertação, buscando sair do encobrimento (DUSSEL, 1993). O desejo de libertação na América Latina (com a educação popular) e o desejo de emancipação na Europa (com a educação social crítica) podem dialogar na medida em que se assentam em teorias críticas. Nesse sentido, uma chave importante para esse diálogo é o caráter político-pedagógico de nossas ações. A educação popular possui forte ligação com movimentos populares e com a concepção contra hegemônica, mas sem a pretensão de institucionalizar-se. Ao contrário, é desejo da educação social crítica a institucionalização e o reconhecimento profissional do educador e da educadora social. O entendimento de que a história não é linear e se constrói entre as contradições da sociedade constitui outra importante chave de leitura. No Brasil, especialmente pelos últimos acontecimentos, essa busca tem se mostrado intermitente, quer dizer, se houve libertação não foi definitiva; de tempos em tempos, há de retomarmos as pautas político-pedagógicas. Tão atual quanto as retomadas é mantermos a esperança freiriana, aquela que não nos incentiva a tão somente esperar, mas a mover-nos (FREIRE, 2005).

4 Em seu nascedouro europeu, há o entendimento de que Pedagogia Social seria a teoria que estuda a educação social, o que discordamos pela tradição dialética a que nos filiamos. Entendemos que a educação social é ou deve ser, ao mesmo tempo, teoria e prática. E mais, por essa mesma dialética entendemos que um diálogo latino-americano com a educação popular só pode ocorrer a partir da educação social crítica. 
Os principais expoentes dessa concepção foram Wolfgang Klafki e Klaus Mollenhauer (CABANAS, 2000; CARIDE, 2005; PÉREZ SERRANO, 2010; VARELA; COTOS, 2010). Klafki vivenciou o nacional-socialismo de Hitler, o que o fez buscar no conceito de emancipação uma forma de libertação do domínio do homem sobre o homem e substitui-lo pela reflexão crítica da realidade buscando mudanças. Gerardo Mondragón e Alfredo Ghiso sintetizam os princípios klafkianos dos quais, em livre tradução ${ }^{5}$, destacamos alguns: a) a construção social da educação decorre de um contexto sócio-histórico determinado; b) a educação social é uma práxis pedagógica; c) o homem e a mulher aprendem em interação uns com os outros, compartilhando trabalhos (VARELA; COTOS, 2010, p. 19). Interessa-nos destacar a atualidade klafkiana expressa na obra Studien zur Bildungstheorie und Didaktik ${ }^{6}$, de 1963, na qual sugere, entre outras proposições, que: 1) propicie a superação das tensões humanas e da vida; e 2) se assente em valores universais como felicidade, justiça, altruísmo e coragem para fazer a história (VARELA; COTOS, 2010).

É possível percebermos uma conexão entre as ideias klafkianas com as freirianas. Para além de terem sido contemporâneos, é notável que tanto na Alemanha era urgente uma emancipação quanto em Nossa América urgia uma libertação. Não resta dúvidas da convergência de ideias quando pensamos na insistência freiriana de que somos seres inacabados e nos completamos, ou nos complementamos, na relação com o outro. "A inconclusão faz parte da natureza do fenômeno vital. Inconclusos somos nós, mulheres e homens" (FREIRE, 1996, p. 55). Na mesma obra, Freire (1996) diz mais:

Sei que ignoro e sei que sei. Por isso, tanto posso saber o que ainda não sei como posso saber melhor o que já sei. E saberei tão melhor e mais autenticamente quanto mais eficazmente construa minha autonomia em respeito à dos outros. [...]. Como professor não me é possível ajudar o educando a superar sua ignorância se não supero permanentemente a minha. (FREIRE, 1996, p. 94-95).

No contexto deste artigo, um bom caminho talvez seja, em meio ao diálogo, estarmos conscientes de que ambos - educadores e educadoras sociais e cidadãos e cidadãs usuários/as - sabem algumas coisas e ignoram outras. Não sejamos, na denúncia de Freire (2004, p. 18), "[...] gente insensível que junta à insensibilidade sua arrogância" e se dá o direito de chamar os outros de "gentalha".

Outro expoente da educação social crítica foi Klaus Mollenhauer, com breve passagem como professor na Universidade de Frankfurt, em 1969 e 1972, indo depois para a docência em Göttingen. Ele defendia a educação social como aquela que "[...] abarca

5 Na obra de Varela e Cotos (2010, p. 19), os trechos escolhidos estão nesta versão: a) La historicidad: la construcción social de la educación sucede en un contexto histórico - social determinado; b) La Pedagogía Social se refiere a la praxis pedagógica; c) El hombre aprende en interacción con otros hombres compartiendo trabajos; d) El ser humano debe ser autónomo y autodeterminado.

6 Do alemão, algo como Estudos sobre a teoria educacional e didática. 
todas aquellas tareas educativas que se suscitan en los lugares conflictivos de la sociedade industrial y que en ésta han venido a hacerse necesarias como medios auxiliares particulares" (MOLLENHAUER apud CABANAS, 2000, p. 23). Entendia como sendo papel do Estado com a sociedade pensar o papel educativo. A educação social crítica tornou-se necessária quando ficou evidente que "[...] las vías educativas tradicionales resultaban ya insuficientes para asegurar el proceso de desarrollo personal" (MOLLENHAUER apud CABANAS, 2000, p. 23). No entendimento de Pérez Serrano (2002, p. 225), Mollenhauer advogava que a educação devia subsidiar situações para que cidadãos e cidadãs "decidan libremente su destino". Pérez Serrano (2002) destaca que entre os aspectos básicos das ideias do pensador estão: a educação social como uma assistência preventiva, um plano diagnóstico, uma proteção vigilante. A educação social para ele está associada a uma tarefa pedagógica ligada a alguma instituição que trabalha ações socioeducativas fora do ambiente escolar.

Um princípio que caracteriza a educação social é o de que "[...] la educación social pretende ayudar al individuo a convertirse em um auténtico ser social, es decir, en uma persona perfectamente socializada" (CABANAS, 2000, p. 33), o que põe em jogo questões ligadas à moral e à ética. Cabanas (2000) busca fundamentos na Filosofia e, sobretudo, na Psicologia para consolidar o que entende como socialização. A educação que se ocupa do social tem algo a ver com a promoção da maturidade social, das relações sociais e com a convivência social.

Nas observações participantes (ANGROSINO, 2009) e nas entrevistas compreensivas (KAUFMANN, 2013), pareceu-nos que um diferencial importante foi entendermos a contribuição da educação social crítica mais precisamente no aspecto ético-moral. Nesse ponto, o professor de Psicologia de Desenvolvimento Moral da Universidade de São Paulo (USP) Yves de la Taille, lembrando Piaget, diz que nossas condutas, nossas socializações são adaptações visando ao "[...] restabelecimento do equilíbrio entre o organismo e o meio. Só agimos se estamos momentaneamente em desequilíbrio" (DE LA TAILLE, 2001, p. 18). Nossas condutas e nossas socializações pretendem, então, nos deixar minimamente tranquilos a fim de que possamos nos desenvolver entre os vários âmbitos da vida (profissional, econômico, social, educacional, psicológico etc.), nem sempre possível por eventuais intercorrências (a falta de renda, por exemplo). Interessa-nos acentuar que nos diversos âmbitos de nossa vida há limites, há - mesmo que não se diga em alto e bom som - condições éticas e morais que nos enlaçam e nos enredam. É na ética, enquanto costumes de uma dada comunidade/sociedade, que estão inseridos conteúdos morais como "[...] um conjunto de normas que, simplificando, dizem 'você tem que respeitar o outro na sua liberdade, na sua dignidade e ser justo com ele"” (DE LA TAILLE, 2014, n.p.). De fato, parece ser o entrelaçamento ético-moral que nos permite viver de modo minimamente civilizado. 
Na pesquisa feita em Novo Hamburgo (RS), percebemos, por exemplo, que, em um jogo de $\mathrm{RPG}^{7}$ (role-playing game), a atividade produzia reflexões sobre a realidade dos e das estudantes. Além da leitura, para criar o cenário e desenvolver a trama do jogo, estudantes eram levados/as pelos educadores e pelas educadoras a (re)pensarem sobre suas realidades/localidades. Havia crianças/adolescentes cujas famílias não possuíam luz, outras não tinham água; assim sendo, como essas ausências influenciariam nas escolhas de um cenário fictício? E que personagem essas crianças/esses adolescentes queriam representar? Que significados poderiam estar implícitos nessas escolhas? Que valores ético-morais traziam as personagens na criação individual de cada estudante? Ao se observar todos os jogadores, o que subjazia em termos de política, social, moral e de ética? Ao olhar para os mapas e as maquetes feitas, que ideia de cidade é possível perceber?

Verificamos que as atividades devem possibilitar momentos de reflexão sobre as realidades dos cidadãos e das cidadãs usuários/as, de modo que eles e elas vão tomando consciência do momento em que vivem e onde pretendem chegar. Esse princípio aliado aos da educação popular podem gerar possibilidades de transformação da realidade.

\section{EDUCAÇÃO PERMANENTE}

No campo escolarizado, a educação permanente não constitui nenhuma novidade. Na política de assistência social, ao contrário, a discussão é bem recente. Desde 2001, compreendeu-se mais claramente a necessidade de alguma capacitação ou formação continuada aos trabalhadores e às trabalhadoras. Ainda assim, eventuais momentos de reflexão continuaram fragmentados (BRASIL, 2013b). Nossas pesquisas demonstraram que, de modo geral, onde havia um/a pedagogo/a este/a se tornava uma espécie de facilitador/a dos encontros formativos.

O documento Política Nacional de Educação Permanente do SUAS - PNEP/SUAS - (BRASIL, 2013b), é um importante instrumento que se alia a outros citados quando tratamos mais especificamente da Assistência Social neste artigo. Aprovado em 2013, ainda está sendo estudado e compreendido sobretudo por governos que terão a responsabilidade de acompanhar as organizações governamentais e não governamentais na implementação do que institui o documento. Ao mesmo tempo, é nosso interesse propor uma compreensão dessa educação a partir da ideia freiriana do inacabamento. Antes, porém, entendamos brevemente a PNEP/SUAS a partir de dois pressupostos.

7 Em linhas gerais, RPG é um gênero de jogo em que se assume o papel de personagens imaginários, em cenários também imaginários. A história é guiada pelo "mestre" que vai narrando a trama. Os jogadores vestem-se, falam e agem como cada personagem foi previamente pensado. O jogo é coletivo desde sua criação e esse coletivo segue durante o jogo pois as ações das personagens dependem de como o mestre vai narrando a história. 
O primeiro pressuposto é o de que trabalhadores e trabalhadoras do Ensino Fundamental, Médio e/ou Superior passem por encontros de capacitação às vezes coletivamente e às vezes mais solitariamente.

\begin{abstract}
O trabalho relacionado à função de provimento de serviços e benefícios é fundado essencialmente em relações sociais e intersubjetivas. Os conhecimentos teóricos, metodológicos e tecnológicos requeridos apresentam uma estreita vinculação com os contextos históricos, econômicos, políticos e socioculturais. Por isso, essa função requer constante análise, reflexão e adequação - por parte dos trabalhadores de práticas profissionais e processos de trabalho, seja no que se refere às relações internas às equipes de trabalho, seja no que diz respeito ao trabalho dirigido diretamente aos cidadãos que demandam as proteções da Assistência Social. (BRASIL, 2013b, p. 30).
\end{abstract}

Por isso, "[...] a Educação Permanente no SUAS deve buscar não apenas desenvolver habilidades específicas, mas problematizar os pressupostos e os contextos dos processos de trabalho e das práticas profissionais realmente existentes" (BRASIL, 2013b, p. 30). São os questionamentos que permitem contínua "[...] atualização e renovação de conceitos, práticas e atitudes profissionais", baseados no movimento histórico e agregando às suas práticas "[...] novos aportes teóricos, metodológicos, científicos e tecnológicos disponíveis" (BRASIL, 2013b, p. 34). Notemos que o documento abre brecha para que as outras educações possam ser tema das reflexões e estimula "[...] uma postura crítica, investigativa e propositiva acerca das experiências vividas no cotidiano do trabalho" (BRASIL, 2013b, p. 35).

O segundo pressuposto da PNEP/SUAS (BRASIL, 2013b) diz respeito à interdisciplinaridade, ou seja, ao não isolamento no trato de questões que se colocam no trabalho das equipes - sejam os profissionais ditos de referência, sejam aqueles "da ponta", os educadores e as educadoras sociais. Nesse sentido, as diferentes visões de cada área podem permitir, ao mesmo tempo, a ampliação do foco de visão profissional como também a construção de novos saberes e práticas. Assim, ganha relevância a aprendizagem significativa traduzida como "[...] uma grande variedade de estratégias instrucionais" (BRASIL, 2013b, p. 37), cuja estrutura vai formando uma cultura de aprendizado permanente nos lugares de trabalho. Em termos de historicidade, leia-se o entendimento de uma forma de sociedade e de um tipo de Estado, o que exige formações/capacitações que "[...] abarquem questões filosófico-científicas e ético-políticas" (BRASIL, 2013b, p. 39), isto é, nas dimensões técnicas (conhecimentos) e ético-políticas (habilidades e atitudes).

Com vistas no aprimoramento de conhecimentos, habilidades e atitudes é que podemos pensar em capacitações e formações. A PNEP/SUAS prevê três tipos de capacitação, com carga horária variável entre 20 e 100 horas/aula. A capacitação introdutória (de 20 a 40 horas/aula) busca ensinar o básico nos temas da assistência social e objetiva o nivelamento de competências necessárias ao andamento dos trabalhos. A capacitação de atualização (de 20 a 100 horas/aula) destina-se a atualizar e manter as competências para o bom andamento dos 
trabalhos. Podem participar dessa capacitação trabalhadores e trabalhadoras, independentemente do nível de formação que possuam, embora, dependendo do tema, seja recomendável capacitações específicas a certos profissionais, em alguns momentos, e capacitações comuns a todos os trabalhadores, em outros momentos. A terceira capacitação é chamada supervisão técnica e desenvolve-se em serviço. A finalidade da supervisão técnica é mobilizar um conjunto de trabalhadores e de trabalhadoras na busca por uma solução diante de alguma demanda específica, quer dizer, "[...] visando à formulação e experimentação de alternativas de solução e superação dos problemas e questões motivadoras" (BRASIL, 2013b, p. 44).

Todas as ações de capacitação no SUAS devem visar os trabalhadores e as trabaIhadoras distribuídos/as em torno de três esferas: na gestão do SUAS; no provimento de serviços e benefícios socioassistenciais (aqui se inserem os educadores e as educadoras sociais que observamos e entrevistamos); e no Controle Social do SUAS. A PNEP/SUAS, aponta Fernandes (2017, p. 125), "[...] valoriza as aprendizagens no trabalho, a construção de saberes a partir das necessidades sociais que permeiam a realidade do trabalhador, assim como os sujeitos de direitos", cidadãos e cidadãs usuários/as. Essa abrangência exige, também, um planejamento das ações. A cada uma dessas ações, a política de educação recomenda que seja gerada certificação aos/às participantes. Mais ainda, que tais certificações sejam consideradas para futuras progressões funcionais. Não menos importante é a recomendação de que os temas a serem abordados nas capacitações sejam eleitos com coletiva participação de trabalhadores e trabalhadoras que compõem a gestão, aqueles e aquelas que atuam nos serviços e benefícios socioassistenciais, bem como dos e das atuantes no controle social do SUAS.

Conforme afirmamos, o documento PNEP/SUAS (BRASIL, 2013b) ainda é objeto de estudos nas instituições. Nossas pesquisas apontaram que a necessidade dessa educação se impõe na medida em que a academia, a universidade, não prepara para as especificidades da assistência social. A título de exemplo, podemos citar a Psicologia que prepara, sobremaneira, o psicólogo para atuar na clínica, enquanto o pedagogo majoritariamente se especializa para o ambiente escolar. Quem prepara para a política de assistência social? Parece haver aqui um inacabamento. Diante dele, propomos uma reflexão a partir de Paulo Freire. Para ele:

A educação é permanente não porque certa linha ideológica ou certa posição política ou certo interesse econômico o exijam. A educação é permanente na razão, de um lado, da finitude do ser humano, de outro, da consciência que ele tem de sua finitude. Mais ainda, pelo fato de, ao longo da história, ter incorporado à sua natureza não apenas saber que vivia mas saber que sabia e, assim, saber que podia saber mais. A educação e a formação permanente se fundam aí. (FREIRE, 2014, p. 25, grifos do autor).

A educação permanente tem a ver com a consciência que temos de nosso inacabamento, pois ela nos impulsiona à mudança. Aprendemos permanentemente com os outros 
quando reagimos "[...] contra toda certeza demasiado certa das certezas" (FREIRE, 2014, p. 22). Podemos compreender, dessa maneira, que a educação permanente poderia ser pensada em duas entrâncias: inicial e permanente de formação-capacitação. A entrância inicial de formação-capacitação incluiria as qualificações de longa duração com carga horária a partir de 1800 horas/aula (Ensino Técnico, Tecnológico, de Graduação e Pós-Graduação), enquanto a entrância permanente de formação-capacitação incluiria as demais ações cuja carga horária variasse entre 20 e 200 horas/aula.

A PNEP/SUAS (BRASIL, 2013b) não diverge dos princípios freirianos, na medida em que visa a "[...] emancipação dos trabalhadores e dos [cidadãos e cidadãs] usuários do Sistema" (BRASIL, 2013b, p. 10). Nessa educação, os temas para reflexão prioritariamente são pensados e escolhidos conjuntamente pelos trabalhadores e pelas trabalhadoras, com formações diversas, a fim de, em conjunto, decidirem o modo como lidar com a questão (FERNANDES, 2012, 2017).

Na educação permanente não se busca culpados por erros; o que se almeja é o pleno conhecimento das necessidades dos sujeitos que procuram atendimento. Por e com eles e elas se organizam e aperfeiçoam os procedimentos e as combinações nas atividades cotidianas. Isso significa dizermos que essa educação também expõe mazelas. Em termos externos, cidadãos e cidadãs usuários/as confiando no atendimento do trabalhador e da trabalhadora expõem as mazelas humanas em busca e na confiança de que receberão a melhor instrução sobre o que fazer ou o melhor atendimento. Em termos internos, por exemplo, poderá vir à tona a realidade da precarização dos trabalhos e dos trabalhadores e das trabalhadoras.

Os lugares pesquisados apresentaram limites. Não raras vezes os estagiários e as estagiárias, em vez de serem aprendizes, executavam o serviço. Contudo, concordamos com Pérez Serrano (1997, p. 373) para quem "[...] los trabajadores sociales son cada vez más conscientes de la necesidad de investigar sobre su próprio trabajo com el fin de mejorarlo". A reflexão no espaço de trabalho é salutar para que não haja meros executores de tarefas, mas educadores e educadoras que contribuam para a mudança que se quer.

A consciência desse inacabamento deve ensejar a participação de outros trabalhadores e de outras trabalhadoras nas formações continuadas, sob a compreensão de que, embora suas profissões estejam devidamente consolidadas (Assistência Social e Psicologia, por exemplo), o traquejo no trabalho com pessoas vulnerabilizadas pode não ter sido objeto de reflexão quando estavam na Graduação.

\section{COMUNHÃO DE PROPÓSITOS}

Entendemos haver um caminho a partir do qual a política de assistência social vem trilhando mudanças; vem-se enveredando de uma visão de polícia para uma de política; do individualismo para uma ação centrada no coletivo, começando pela família (em sua multiformidade); da ideia de favor à noção de cidadania - que faz com que usuários e usuárias 
se tornem, antes, cidadãos e cidadãs e depois usuários e usuárias. Percebemos mais claramente a necessidade de atualização na cosmovisão dos serviços de socorro às pessoas que, por diversas situações, estão em condições vulnerabilizadas. O objetivo das mudanças induzidas pelas normativas está claramente descrito nos dois documentos que utilizamos do Ministério do Desenvolvimento Social e Combate à Fome (atualmente denominado Ministério da Cidadania). O primeiro, Tipificação Nacional de Serviços Socioassistenciais (BRASIL, 2013a, p. 9), busca "[...] mudanças efetivas e duradouras em sua condição de vida, na perspectiva do fortalecimento de sua autonomia e cidadania". O segundo documento, Política Nacional de Educação Permanente do SUAS (BRASIL, 2013b, p. 7), em sua apresentação, enfatiza a necessidade da qualificação profissional "[...] comprometida com um projeto emancipatório de sociedade". Em síntese, podemos dizer que a política de assistência social tem em seu horizonte a mudança social a partir da autonomia, da emancipação dos cidadãos e das cidadãs usuários/as.

Na mesma direção vão as educações que escolhemos como referência e aqui as sintetizamos (Quadro 2). A educação não escolar se centra na formação humana que transcende a burocratização e a institucionalização escolar, estendendo-se ao longo da vida. A educação popular, por essência, nasce fora do ambiente escolar em meio às lutas populares de libertação das ditaduras latino-americanas. Sua vocação é libertadora e seu intento maior é a mudança da realidade social, incluindo uma compreensão histórico-política da realidade da qual quer se libertar. A educação social crítica vem na mesma toada quando, para além das realidades social, histórica e política, enfatiza a consciência de que há fundamentos ético-morais nos movimentos de socialização. A educação permanente, a partir da concepção de que somos seres inacabados (FREIRE, 1996, 2005, 2014), também visa à mudança e ao aperfeiçoamento dos espaços de participação e consolidação da cidadania.

Quadro 2 - Quadro-síntese das Educações de Referência

\begin{tabular}{|c|c|c|c|c|}
\hline & $\begin{array}{l}\text { Educação não } \\
\text { escolar }\end{array}$ & Educação popular & $\begin{array}{c}\text { Educação social } \\
\text { crítica }\end{array}$ & $\begin{array}{l}\text { Educação permanen- } \\
\text { te }\end{array}$ \\
\hline Origem & Grécia Antiga & América Latina & $\begin{array}{c}\text { Europa } \\
\text { (Alemanha) }\end{array}$ & Brasil \\
\hline Sujeitos & $\begin{array}{l}\text { Todas as práticas } \\
\text { intencionais que } \\
\text { se dão fora da } \\
\text { escola ou que, } \\
\text { na escola, não } \\
\text { tenham a ver } \\
\text { com conteúdos } \\
\text { escolares. }\end{array}$ & $\begin{array}{l}\text { Pessoas que } \\
\text { compõem os } \\
\text { ambientes esco- } \\
\text { lar e não escolar. } \\
\text { Forte ligação com } \\
\text { os movimentos } \\
\text { sociais populares. }\end{array}$ & $\begin{array}{l}\text { A priori restrita } \\
\text { ao ambiente não } \\
\text { escolar. Destina- } \\
\text {-se a sujeitos que } \\
\text { possuem alguma } \\
\text { desvantagem ou } \\
\text { vulnerabilidade } \\
\text { social. }\end{array}$ & $\begin{array}{l}\text { Profissionais que } \\
\text { buscam qualificar-se. } \\
\text { Tem início quando o } \\
\text { sujeito opta por uma } \\
\text { formação específica } \\
\text { (Psicologia, Peda- } \\
\text { gogia, Assistência } \\
\text { Social) e prossegue } \\
\text { quando, já atuando } \\
\text { em alguma área, o } \\
\text { sujeito passa a ter } \\
\text { formação/qualificação } \\
\text { no e para o trabalho } \\
\text { que exerce. }\end{array}$ \\
\hline
\end{tabular}




\begin{tabular}{|c|c|c|c|c|}
\hline $\begin{array}{l}\text { Pressupostos } \\
\text { teóricos }\end{array}$ & $\begin{array}{l}\text { Compreender } \\
\text { criticamente os } \\
\text { conceitos de edu- } \\
\text { cação formal, não } \\
\text { formal e informal. }\end{array}$ & $\begin{array}{l}\text { Ação intencional, } \\
\text { de cunho políti- } \\
\text { co-pedagógico } \\
\text { contra hegemô- } \\
\text { nico que visa a } \\
\text { transformar a rea- } \\
\text { lidade das classes } \\
\text { populares. }\end{array}$ & $\begin{array}{l}\text { Promover, de- } \\
\text { fender e garan- } \\
\text { tir os direitos } \\
\text { de cidadãos e } \\
\text { cidadãs usuários/ } \\
\text { as da política de } \\
\text { assistência social. } \\
\text { Dialoga com prin- } \\
\text { cípios de direitos } \\
\text { humanos. Busca } \\
\text { a transformação } \\
\text { social enfatizando } \\
\text { conteúdos ético- } \\
\text {-morais. }\end{array}$ & $\begin{array}{l}\text { Dispor-se a aprender } \\
\text { continuamente, inse- } \\
\text { rindo-se em pesqui- } \\
\text { sas. }\end{array}$ \\
\hline Metodologia & $\begin{array}{l}\text { Observação parti- } \\
\text { cipante, pesquisa } \\
\text { participante, en- } \\
\text { trevistas, grupos } \\
\text { de discussão, } \\
\text { grupos de estu- } \\
\text { dos. }\end{array}$ & $\begin{array}{l}\text { Observação parti- } \\
\text { cipante, pesquisa } \\
\text { participante, entre- } \\
\text { vistas, grupos de } \\
\text { discussão, grupos } \\
\text { de estudos. }\end{array}$ & $\begin{array}{l}\text { Observação parti- } \\
\text { cipante, pesquisa } \\
\text { participante, en- } \\
\text { trevistas, grupos } \\
\text { de discussão, } \\
\text { grupos de estu- } \\
\text { dos. }\end{array}$ & $\begin{array}{l}\text { Observação partici- } \\
\text { pante, pesquisa par- } \\
\text { ticipante, entrevistas, } \\
\text { grupos de discussão, } \\
\text { grupos de estudos. }\end{array}$ \\
\hline Característica & $\begin{array}{l}\text { Não tem preocu- } \\
\text { pação com certifi- } \\
\text { cação. Liberdade } \\
\text { curricular. Sem } \\
\text { tempo pré-de- } \\
\text { terminado para } \\
\text { conclusão de } \\
\text { atividades. }\end{array}$ & $\begin{array}{l}\text { Tem forte conteú- } \\
\text { do político-peda- } \\
\text { gógico, visando a } \\
\text { transformação das } \\
\text { realidades sociais. }\end{array}$ & $\begin{array}{l}\text { Ação pedagógica } \\
\text { intencional que } \\
\text { busca trans- } \\
\text { formação das } \\
\text { realidades sociais } \\
\text { de cidadãos e ci- } \\
\text { dadãs na iminên- } \\
\text { cia ou sob risco } \\
\text { em razão das } \\
\text { vulnerabilidades } \\
\text { sociais. }\end{array}$ & $\begin{array}{l}\text { Possui graus de certi- } \\
\text { ficação/acreditação. }\end{array}$ \\
\hline
\end{tabular}

Fonte: Os autores, 2021.

A partir do Quadro 2, podemos dizer que as educações mantêm relações de proximidade. A educação não escolar enfatiza que as aprendizagens não se restringem ao espaço institucional e consagrado da sala de aula; ao mesmo tempo que confere uma função ocupacional aos trabalhadores e às trabalhadoras que planejam suas atividades pedagógicas não sem algumas formalidades. A educação popular, consolidada como referência em movimentos sociais e populares, constitui-se como referência político-pedagógica ao se aproximar de cidadãos e cidadãs usuários/as para, com eles e elas, buscarem a emancipação. A educação social crítica contribui na emancipação, uma vez que se ocupa do social com vistas à promoção, à defesa e à garantia dos direitos da cidadania de pessoas que estão majoritariamente à margem, nas periferias das cidades. A essa conscientização de que há direitos se somam princípios éticos e morais dos quais não podemos escapar quando se pensa em uma sociedade justa e igualitária. Por fim, a educação permanente contribui em três aspectos: 1) não somos completos, mas, sim, inacabados; 2) a aprendizagem dá-se ao longo de toda a vida; 3 ) a possibilidade de pensar-se formações iniciais e continuadas, inclusive no e para o serviço. 
A convergência emancipatória pode ocorrer na medida em que as educações e a política de assistência social visam o mesmo objetivo: uma mudança na sociedade, na qual todos e todas venham a possuir um mínimo necessário para a dignidade humana. Como nossa sociedade é múltipla e múltiplas são as razões das vulnerabilidades (MARANDOLA JR.; HOGAN, 2006), parece ser coerente que nos utilizemos de educações ao pensar as práticas educativas. Paulo Freire, em diálogo com Ira Shor, disse que, quando era professor de português buscando bem ensinar, fazia uma mistura de formas didáticas (FREIRE; SHOR, 1986, p. 39). Essas formas didáticas, por seu turno, podem estar abrigadas em distintas perspectivas pedagógicas, aqui identificadas como educações.

\section{CONSIDERAÇÕES FINAIS}

O objetivo deste artigo foi compartilhar pesquisa feita com educadores e educadoras sociais que trabalham no Serviço de Convivência, com crianças e adolescentes. Inicialmente, apresentamos o campo da política de assistência social, destacando as normativas que o sustentam e que sugerem o caminho da emancipação a ser seguido. Na sequência, trouxemos as educações que referenciaram nosso olhar nos lugares pesquisados, não as pormenorizando, tendo em vista a existência de ampla bibliografia à disposição e ao reduzido espaço de um artigo.

Procuramos ilustrar com exemplos advindos das pesquisas e esboçamos um quadro-síntese das educações com a finalidade de tornar mais visíveis as possíveis contribuições das educações ao campo da política de assistência social. Sobressai nelas o apelo à transformação social.

Ao enfatizarmos que as normativas do campo da assistência social estimulam a emancipação, o que se coaduna com as teorias críticas da educação, trouxemos uma compreensão do conceito de emancipação e exemplos de como o vimos nas práticas observadas. Isso nos permite apontar a temporalidade dos sinais emancipatórios, pois as compreensões vão mudando com o passar dos dias e a consequente conscientização proporcionada a partir das educações.

A educação acontece na política de assistência social assim como acontece na vida individual e coletiva. Está presente no asseio dos ambientes e de trabalhadores e trabaIhadoras que recebem as famílias para atendimento assim como na forma como se acolhe quem precisa de socorro do Estado; igualmente, quando se reúne para pensar aprimoramentos nas práticas educativo-pedagógicas. Não menos educativo é o movimento em que se prepara e se serve a alimentação aos que dela carecem, sem contar os diversos instantes em que devemos ouvir esses cidadãos e essas cidadãs usuários/as, a fim de, com eles/ elas, contribuirmos na superação de suas condições.

Nosso desejo é contribuir para um debate que parece fundamental - o da possibilidade de aprendermos permanentemente -, conjugando alternativas pedagógicas que 
As educações na política de assistência social...

dialogam entre si e que comungam a intencionalidade emancipatória. O exercício realizado nesta pesquisa revela tanto a possibilidade de diálogo entre perspectivas distintas de educação, quanto o envolvimento com campos científicos diferentes, os tão necessários avanços na criação de uma sociedade mais justa e para os necessários avanços civilizatórios. 


\section{REFERÊNCIAS}

ADORNO, Theodor W. Educação e emancipação. Rio de Janeiro: Paz e Terra, 1995.

ANGROSINO, Michael. Etnografia e observação participante. Porto Alegre: Artmed, 2009.

BEISIEGEL, Celso de Rui. Política e educação popular. A teoria e a prática de Paulo Freire no Brasil. 3. ed. São Paulo: Ática, 1992.

BRANDÃO, Carlos Rodrigues. O que é educação. São Paulo: Brasiliense, 2007.

BRASIL. Lei № 8.742, de 7 de dezembro de 1993. Dispõe sobre a organização da Assistência Social e dá outras providências. Brasília: Presidência da República, Casa Civil, Subchefia para Assuntos Jurídicos, [1993]. Disponível em: http://www.planalto.gov.br/ccivil_03/leis/l8742compilado.htm. Acesso em: 9 dez. 2021.

BRASIL. Tipificação Nacional de Serviços Socioassistenciais. Brasília: Ministério do Desenvolvimento Social e Combate à Fome, Secretaria Nacional de Assistência Social, 2013a.

BRASIL. Política Nacional de Educação Permanente do SUAS. Brasília: Ministério do Desenvolvimento Social e Combate à Fome, 2013b.

CABANAS, José Maria Quintana. Pedagogia social. 2. ed. reimp. Madrid: Dykinson, 2000.

CABANAS, José Maria Quintana. Antecedentes históricos de la educación social. In: PETRUS, Antoni. (coord.). Pedagogia social. Barcelona: Editorial Ariel S/A, 1997. p. 68-91.

CARIDE, José Antonio. Las fronteras de la Pedagogía Social: perspectivas científica e histórica. Barcelona: Editorial Gedisa, 2005.

DE LA TAILLE, Yves. Limites: três dimensões educacionais. 3. ed. São Paulo: Ática, 2001.

DE LA TAILLE, Yves. Palestra: Conflito, Violência, Moral e Ética por Yves de la Taille, 2014. 1 vídeo (22 min 33 s). Publicado pelo canal Socrates Da Vinci. Disponível em: https://www.youtube.com/watch?v=gq0QGI4bHhY. Acesso em: 9 dez. 2021.

DUSSEL, Enrique. 1492: o encobrimento do outro: a origem do mito da modernidade. Petrópolis: Vozes, 1993.

FÁVERO, Osmar. Paulo Freire, movimentos sociais e educação de jovens e adultos. In: STRECK, Danilo R.; ESTEBAN, Maria Teresa. (org.). Educação popular: lugar de construção social coletiva. Petrópolis: Vozes, 2013. p. 49-63.

FERNANDES, Rosa Maria Castilhos. Educação permanente nas situações de trabalho de assistentes sociais. Trabalho, Educação e Saúde, Rio de Janeiro, v. 10, n. 3, p. 481-505, nov. 2012. DOI: https://doi.org/10.1590/S1981-77462012000300008

FERNANDES, Rosa Maria Castilhos. Processos de educação permanente nas situações de trabaIho no SUAS. Sociedade em debate, Pelotas, v. 23, n. 2, p. 121-147, jul./dez. 2017. 
As educações na política de assistência social...

FERRARO, Alceu Ravanello. História inacabada do analfabetismo no Brasil. São Paulo: Cortez, 2009.

FREIRE, Paulo. Pedagogia da autonomia: saberes necessários à prática educativa. 27. ed. São Paulo: Paz e Terra, 1996.

FREIRE, Paulo. À sombra desta mangueira. 4. ed. São Paulo: Olho d'Água, 2004.

FREIRE, Paulo. Pedagogia do oprimido. 44. ed. Rio de Janeiro: Paz e Terra, 2005.

FREIRE, Paulo. Política e educação. Organização Ana Maria de Araújo Freire. São Paulo: Paz e Terra, 2014.

FREIRE, Paulo; SHOR, Ira. Medo e ousadia: o cotidiano do professor. Rio de Janeiro: Paz e Terra, 1986.

GADOTTI, Moacir. Educação Popular, Educação Social, Educação Comunitária: conceitos e práticas diversas, cimentadas por uma causa comum. Revista Diálogos: pesquisa em extensão universitária, Brasília, v. 18, n. 1, p. 10-32, dez. 2012.

KAUFMANN, Jean-Claude. A entrevista compreensiva: um guia para pesquisa de campo. Petrópolis: Vozes; Maceió: Edufal, 2013.

LEFÈVRE, Fernando. Discurso do sujeito coletivo. Nossos modos de pensar, nosso eu coletivo. São Paulo: Andreoli, 2017.

LEMES, Marilene Alves. Estratégias de participação na política de assistência social na perspectiva de Paulo Freire. 2017. 189 f. Tese (Doutorado em Educação) - Universidade do Vale do Rio dos Sinos, São Leopoldo, 2017.

LIBÂNEO, José Carlos. Pedagogia e pedagogos pra quê? São Paulo: Cortez, 2002.

MARANDOLA JR., Eduardo; HOGAN, Daniel Joseph. As dimensões da vulnerabilidade. São Paulo em Perspectiva, São Paulo, v. 20, n. 1, p. 33-43, jan./mar. 2006.

MARTINS, Marcos Francisco. Educação não escolar: discussão terminológica e mapeamento dos fundamentos das tendências. Revista Contrapontos, Itajaí, v. 16, n. 1, p. 40-61, 2016. DOI: http:// dx.doi.org/10.14210/contrapontos.v16n1.p40-61

MEJÍA, Marco Raúl. Educação e pedagogias críticas a partir do Sul: cartografias da educação popular. São Carlos: Pedro e João Editores, 2018.

MIRA, Levi Nauter de. As educações na política de assistência social: um olhar para o serviço de convivência e fortalecimento de vínculos. 2020. 198 f. Tese (Doutorado em Educação) - Universidade do Vale do Rio dos Sinos, São Leopoldo, 2020.

MOURA, Eliana Perez Gonçalves de; ZUCCHETTI, Dinora Tereza. Explorando outros cenários: educação não escolar e pedagogia social. Revista Unisinos de Educação, São Leopoldo, v. 10, n. 3, p. 228-236, 2006. 
MOURA, Eliana Perez Gonçalves de; ZUCHETTI, Dinora Tereza. Educação além da escola: acolhida a outros saberes. Cadernos de Pesquisa, São Paulo, v. 40, n. 140, p. 629-648, maio/ago. 2010. DOI: https://doi.org/10.1590/S0100-15742010000200016

PAIVA, Vanilda. História da educação popular no Brasil: educação popular e educação de adultos. 6. ed. São Paulo: Loyola, 2003.

PÉREZ SERRANO, Gloria. Investigación en educación social. Metodologías. In: PETRUS, Antoni. (coord.). Pedagogia social. Barcelona: Editorial Ariel S/A, 1997. p. 372-401.

PÉREZ SERRANO, Gloria. Origen y evolución de la Pedagogía Social. Pedagogía Social. Revista Interuniversitaria, Sevilla, n. 9, p. 193-231, dez. 2002.

PÉREZ SERRANO, Gloria. Pedagogía social - Educación Social: construcción científica e intervención práctica. 4. ed. Madrid: Narcea, 2010.

PETRUS, Antoni (coord.). Pedagogia social. Barcelona: Editorial Ariel S/A, 1997.

PRADO, Maria Ligia; PELLEGRINO, Gabriela. História da América Latina. São Paulo: Contexto, 2016.

SPOSATI, Aldaíza. Assistência Social: da ação individual ao direito social. Revista Brasileira de Direito Constitucional - RBDC, [s. I.], n. 10, p. 435-458, jul./dez. 2007.

STRECK, Danilo R.; ADAMS, Telmo. Pesquisa participante, emancipação e (des)colonialidade. Curitiba: CRV, 2014.

VARELA, Gerardo Mondragón; COTOS, Alfredo Ghiso. Pedagogia social. 2. ed. Santiago de Cali: Universidad del Valle, 2010. 